\title{
Implications of Distributed Ledger Technologies on Firm Cost Structure and Supply Chain Integration
}

\author{
Medici $\mathbf{M}^{1}$, D Wrachien $\mathbf{D}^{2 *}$ and Canavari $\mathbf{M}^{1}$ \\ ${ }^{1}$ Alma Mater Studiorum-Università di Bologna, Viale Giuseppe Fanin 50, Bologna, Italy \\ ${ }^{2}$ State University of Milan, via Celoria 2, Milan, Italy
}

*Corresponding author: Daniele De Wrachien, State University of Milan, via Celoria 2, Milan,

\section{Editorial}

Volume 5 Issue 2

Received Date: July 07, 2020

Published Date: July 15, 2020

DOI: $10.23880 /$ oajar-16000241 Italy, Email: daniele.dewrachien@unimi.it

\section{Introduction}

Technological infrastructures based on distributed ledger technologies (DLTs) like blockchain technology (BCT) are new digital technologies combining peer-topeer networking and cryptography to create immutable public ledgers characterized by decentralization, collective maintenance, consensus trust and reliable data. DLT, today considered as an interdisciplinary topic, is expected to transform current economic organization and governance [1], and can be considered one of the evolutionary next steps for agriculture, particularly for current state-of-the-art of precision agriculture [2].

From the economic perspective, infrastructures based on DLT depict favourable conditions to lower transaction costs for the enterprise adopting such technology, through costless verification and without the need for costly intermediation.

Even though the DLT application to agriculture is somehow underachieved [3], it would be interesting to understand how such technology adoption in agriculture can re-shape firm boundaries. Investigating the extent to which the single firm can increase its integration with other sellers and buyers of the value chain, both in the view of the single actor and a whole value chain perspective, is extremely important.

\section{Underlying Theory: Transaction Cost Economics}

Coase explained the nature of the firm comparing it to the market. Rather than consisting exclusively of independent people who contract goods with one another $[4,5]$, economic agents tend to organize their relations in a hierarchical way, which gives way to perform transactions more efficiently [6]. As such, the firm emerges as a more efficient organization than the market. A firm continues to expand its boundaries until the costs of internal organization exceed the cost of transactions on the market. Thus, the efficiency of different governance structure is determined by transaction costs.

\begin{tabular}{|c|c|c|}
\hline Governance structure & Characteristics & Example \\
\hline 1. Spot markets & $\begin{array}{c}\text { Generic goods and services. Identities of the parties involved } \\
\text { are immaterial to the transaction }\end{array}$ & Commodity markets \\
\hline $\begin{array}{l}\text { 2. Simple short-term } \\
\text { contracts }\end{array}$ & $\begin{array}{l}\text { Low degree of information exchange like terms of payment } \\
\text { and low to mid customization }\end{array}$ & Low customized contract farming \\
\hline $\begin{array}{l}\text { 3. Long-term } \\
\text { contracts }\end{array}$ & $\begin{array}{l}\text { Medium degree of information exchange like terms } \\
\text { of payment, adjustment clauses, with mid to complex } \\
\text { customization }\end{array}$ & $\begin{array}{l}\text { Contract farming with } \\
\text { recommended production } \\
\text { methods }\end{array}$ \\
\hline $\begin{array}{l}\text { 4. Relational } \\
\text { contracts }\end{array}$ & $\begin{array}{l}\text { High degree of information exchange, with focus on the } \\
\text { parties' relationship and possible term re-negotiation }\end{array}$ & Verbal agreement \\
\hline 5. Vertical integration & Several supply chain activities are carried out by the firm & Governance agreements \\
\hline
\end{tabular}

Table 1: The various type of transactions Adapted from [8]. 
Markets are places in which buyers and sellers voluntarily exchange goods and services. For an exchange to be executed, the parties need to verify the key attributes of that transaction. In general, buyers and sellers incur into transaction costs when they cannot easily verify all the relevant attributes of a specific transaction by themselves [7]. Also, numerous market exchanges with third-parties involved, in addition to transaction cost, require some degree of information disclosure, which poses a privacy problem and could be exploited by other market participants to establish market power (ibid).

The spectrum of governance structures in which transactions occur range from spot markets to fully integrated organizations. An example of the spectrum of governance structures is shown in Table 1.

\section{Distributed Ledgers as Institutional Technology}

DLT was introduced about ten years ago as the underlying BCT infrastructure for the Bitcoin payment system, and it is used today in many applications, particularly in the field of finance: cryptocurrencies and digital payment systems allow to transfer transactions safely and transparently, without the need for intermediaries. Further developed applications deal with track-and-trace and quality measurement solutions in the field of logistics supporting the so-called smart contracts.

In this context, DLT has the possibility of changing business processes, firm's value creation and supply chain networks, by tracking, recording and controlling the assets involved. These features depict DLT as an institutional innovation, i.e. a technology for economic coordination, potentially capable of substituting the economic coordination provided by markets, hierarchies, relational contracting and governments [9].

As the cost of verification has fallen through history, market transactions have become more efficient [7]. Digitization and the Internet have pushed verification costs for many types of transactions close to zero and have increased security with protocols. DLT has the real potential to carry this process forward, with the possibility of reliably transferring value between distant parties without the need for costly intermediaries and allowing a drastic reduction in verification and networking costs. Also, DLT can reduce imperfect information that may lead to unbalanced market power, thereby increasing transaction efficiency and contributing again to decrease transaction costs.

\section{Conclusion}

Thanks to its intrinsic ability in reducing transaction costs, DLT can really change the scope of intermediation in the agriculture and food sector. The analysis of how novel technology can change transactions in the supply chain is a move towards a sectorial level of analysis, which is a necessary step to bring value chain analysis into relevance also for policy-makers [10].

Future efforts may be focused on the measurement of the extent to which DLT can reduce transaction costs effectively and re-shape the institutional boundaries of economic coordination. As a consequence, it may contribute to shifting the governance structure to modes of coordination approaching vertical integration. In this regard, the trade-off between the costs of internal organization and the transaction costs may be formulated in terms of an optimization problem to measure the extent the firm change its integration pattern with other supply chain actors following the adoption of DLT.

\section{References}

1. Davidson S, De Filippi P, Potts J (2016) Economics of Blockchain. SSRN Electronic Journal, pp: 23.

2. Antonucci F, Figorilli S, Costa C, Pallottino F, Raso, et al. (2019) A review on blockchain applications in the agri-food sector. In Journal of the Science of Food and Agriculture 99(14): 6129-6138.

3. Lin YP, Petway J, Anthony J, Mukhtar H, Liao SW, et al. (2017) Blockchain: The Evolutionary Next Step for ICT E-Agriculture. Environments 4(3): 50.

4. Coase RH (1937) The Nature of the Firm, Economica, New Series 4(16): 386-405.

5. Coase RH (1960) The Problem of Social Cost. The Journal of Law and Economics 3: 1-44.

6. Williamson OE (1985) The Economic Institutions of Capitalism: firms, markets, relational contracting. New York.

7. Catalini C, Gans JS (2020) Some simple economics of the blockchain. Communications of the ACM 63(7): 80-90.

8. Pint EM, Baldwin L (1997) Strategic sourcing: Theory and evidence from economic and business management. Prepared for the U.S. Air Force by RAND's Project AIR FORCE ISBN: 0-8330-2533-3

9. Davidson S, De Filippi P, Potts J (2018) Blockchains and the economic institutions of capitalism. In Journal of Institutional Economics 14(4): 639-658.

10. Schmitz PW (2005) Information Gathering, Transaction Costs and the Property Rights Approach. CEPR Discussion Paper No. 5417, pp: 30. 